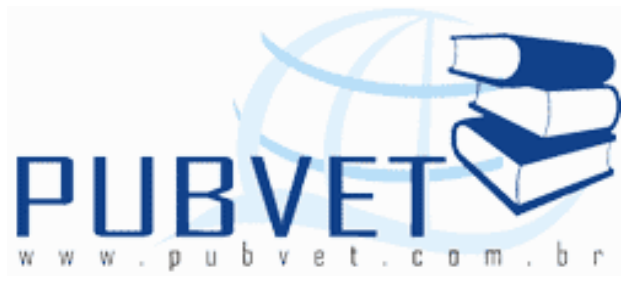

PUBVET, Publicações em Medicina Veterinária e Zootecnia.

\title{
Exigências de compostos fibrosos para bovinos em confinamento
}

Wanderson José Rodrigues de Castro ${ }^{1}$, Michele Carolina Rodrigues de Castro ${ }^{2}$, Geferson Antonio Fernandes ${ }^{3}$, Fabíola Francisca Dias Fernandes ${ }^{4}$, Claudio Jonasson Mousquer ${ }^{1}$, Vitor Tavares Oliveira Borges ${ }^{1}$, Tiago Adriano Simioni ${ }^{5}$, Alvair Hoffmann ${ }^{5}$

1 Mestrando em Ciência Animal da Universidade Federal de Mato Grosso, Campus Cuiabá-MT

${ }^{2}$ Bióloga, Universidade Federal de Mato Grosso, campus de Rondonópolis-MT

${ }^{3}$ Zootecnista - UFMT, Sinop-MT

${ }^{4}$ Medica Veterinária - UFMT, Sinop-MT

${ }^{5}$ Mestrando em Zootecnia da Universidade Federal de Mato Grosso, Campus Sinop-MT

\section{Resumo}

O objetivo desse trabalho foi, tracionar métodos e mecanismos de utilização da fibra em dietas de ruminantes em confinamentos, o que se torna indispensável sua utilização, obtendo melhores índices zootécnicos e saúde aos animais confinados. Hoje em dia a busca pela terminação rápida de animais em confinamento vem se tornando uma pratica bastante comum; dietas com alta proporção volumoso $x$ concentrado vem sendo bastante utilizada nos grandes confinamentos, além de terminar os animais mais cedo os custos com essa 
CASTRO, W.J.R. et al. Exigências de compostos fibrosos para bovinos em confinamento. PUBVET, Londrina, V. 8, N. 3, Ed. 252, Art. 1667, Fevereiro, 2014.

dieta se torna mais rentável pois não há necessidade de grandes áreas para plantação de volumosos, a fibra que é essencial para manter a saúde no rumem do animal pode ser oriunda de fontes da agroindústria como por exemplo o bagaço de cana in natura, porém seu uso tem que ser aplicado com bastante cautela já que seu valor nutricional é baixo e sua única função é substituir a fibra.

Palavras-chave: Fibra, Rumem, Terminação

\title{
Requirements for compounds fibrous cattle in containment
}

\begin{abstract}
The aim of this work was, traction methods and mechanisms for the use of fiber in the diet of ruminants in feedlots, which becomes indispensable use, obtaining better performance indexes and health to confined animals. Nowadays the search for quick termination of animals in confinement is becoming a fairly common practice; diets with high roughage $x$ concentrate has been widely used in large feedlots, and finished animals early costs with this diet is becomes more profitable because there is no need for large areas for planting bulky fiber which is essential for maintaining the health of the animal in the rumen can be derived from agro-industrial sources such as sugar cane bagasse in natura, but its use must be applied with considerable caution as its nutritional value is low and its only function is to replace the fiber.
\end{abstract}

Keywords: Fiber, Rumen, Termination

\section{Introdução}

O confinamento de bovinos para corte passou a ter expressão no País, a partir de 1980, como uma prática de engorda intensiva de animais, via fornecimento de alimentação adequada nos meses de inverno, ou seja, no período onde a produção de forragem diminui seu crescimento devido a fatores 
CASTRO, W.J.R. et al. Exigências de compostos fibrosos para bovinos em confinamento. PUBVET, Londrina, V. 8, N. 3, Ed. 252, Art. 1667, Fevereiro, 2014.

climáticos Wedekin e Amaral, (1991). Essa prática surgiu como uma alternativa de oferta de animais para abate nos meses de escassez mais acentuada e, também, como uma opção de investimento ao pecuarista, pela melhor possibilidade de capitalização ditada pelos preços mais atrativos da entressafra Wedekin et al. (1994). As principais vantagens apontadas por Velloso (1984), ao se conduzir a engorda de bovinos em confinamento, são: redução da idade de abate, maior rendimento das carcaças, obtenção de carne de ótima qualidade em períodos de maior escassez, mortalidade quase nula, possibilidade de exploração intensiva em pequenas propriedades, retorno mais rápido do capital de giro investido na engorda, entre outras.

De modo geral, o processo requer tecnologia mais avançada e adequada, que envolve a seleção dos animais (pela grande variabilidade, principalmente em termos de potencial genético), a infraestrutura necessária na propriedade, atentar aos preços de mercado na hora da venda e principalmente a alimentação que corresponde em torno de 70 a $80 \%$ do custo final, onde é o "gargalo" do sucesso do confinamento. Todavia, com a reduzida margem de lucro dos confinamentos, produtores, empresas e pesquisadores têm buscado alcançar o equilíbrio entre os custos e qualidade nas dietas, e o uso de dietas com alto teor de concentrado tem sido a opção da maior parte dos confinadores, porém essa dieta rica em grãos pode provocar distúrbios nos animais caso não seja balanceada adequadamente.

De acordo com Freitas Neto (2011) Para melhor utilização dessas dietas com alto teor de energia é necessário um correto balanceamento dos carboidratos na dieta. Os carboidratos são divididos em carboidratos fibrosos (fibra) e carboidratos não fibrosos, no caso de dietas com maior teor de concentrado é rica em carboidrato não fibroso. A fibra é a fração dos carboidratos dos alimentos de digestão lenta ou indigestível, que pode limitar o consumo de matéria seca. Mas, a fibra é fundamental para manter a saúde do rúmen e de todo o trato digestório, pois estimula a atividade de mastigação e 
CASTRO, W.J.R. et al. Exigências de compostos fibrosos para bovinos em confinamento. PUBVET, Londrina, V. 8, N. 3, Ed. 252, Art. 1667, Fevereiro, 2014.

a produção de saliva que, por ser rica em bicarbonato, faz o tamponamento, evitando quedas acentuadas do $\mathrm{pH}$ ruminal.

Todavia um dos pontos importantes que podem limitar o nível de produtividade na produção de ruminantes, isto é, maiores ganhos de peso em um intervalo mais curto, é o consumo Zanine e Macedo (2002). O consumo é regulado por vários fatores, tais como: alimento (fibra, densidade energética, volume), animal (peso, nível de produção e estado fisiológico) e condição de alimentação (disponibilidade de alimento, frequência de alimentação, dentre outros) como descrito por Mertens (1987). Sendo assim dentre estes fatores que foram expostos que controlam o consumo teremos um foco maior nos compostos fibrosos.

\section{Conceito de fibra}

A definição de fibra está vinculada ao método analítico empregado em sua determinação Mertens (2001), sendo assim, é considerado um termo meramente nutricional. De modo geral, a fibra tem sido definida como: 1) o componente estrutural das plantas; 2) a fração menos digestível do alimento; 3) a fração do alimento que não pode ser digerida pelas enzimas dos mamíferos; e 4) a fração do alimento que promove a ruminação e a saúde do rúmen Weiss (1993).

Quimicamente, a fibra é um agregado de compostos e não uma entidade química distinta, portanto, a composição química da fibra é dependente da sua fonte e da metodologia usada na sua determinação laboratorial Mertens (1997). A fibra insolúvel em detergente neutro (FDN) representa a fração de carboidratos estruturais dos alimentos (parede celular) e tem sido relacionada à regulação da ingestão de alimentos, digestibilidade, taxa de passagem e atividade mastigatória dos ruminantes Rodrigues (1998). De acordo com Macedo Junior et al. (2007) o método para determinação da fibra deve estar de acordo com princípios biológicos ou com sua utilidade 
CASTRO, W.J.R. et al. Exigências de compostos fibrosos para bovinos em confinamento. PUBVET, Londrina, V. 8, N. 3, Ed. 252, Art. 1667, Fevereiro, 2014.

empírica, além disso, o método deve apresentar acurácia analítica, alta repetibilidade, praticidade e baixo custo.

A concentração de fibra nas dietas de ruminantes tem sido associada com a regulação do consumo, digestibilidade, taxa de passagem e atividade de mastigação Carvalho e Kieling, (2002). Devido à lenta degradação e baixa taxa de passagem da fibra no rúmen, de rações ricas em fibra, cuja densidade energética é baixa, ocorre limitação do consumo pelo enchimento ou distensão física deste compartimento. Por outro lado, nas rações que possuem baixo conteúdo de fibra há redução no pH do rúmen, diminuição da fermentação e ocorrência de distúrbios metabólicos Mertens (1997).

\section{FDN efetivo e fisicamente efetivo}

Mertens (1997) relatou que, embora a determinação da concentração de FDN possa ser considerada como de rotina, a efetividade da fibra tem sido definida sob diferentes formas. Segundo ele, tradicionalmente, as definições têm se referido à habilidade da fibra para manter a produção de gordura do leite e a saúde do animal "efetivamente". Assim, na busca de definições mais pontuais, dois novos e distintos conceitos, que possibilitassem a introdução de um sistema para determinação de fibra efetiva em alimentos foram apresentados Mertens (1997): FDN fisicamente efetiva (FDNfe) e FDN efetiva (FDNe).

Bianchini et al. (2007) cita que a FDN efetiva está relacionada com a habilidade total de um alimento em diminuir a fibra de maneira que a percentagem de gordura no leite não se altere. A FDN fisicamente efetiva está relacionada com as propriedades físicas da fibra (principalmente o tamanho da partícula) que estimula a atividade de mastigação e estabelece uma estratificação bifásica dos conteúdos ruminais (uma camada flutuante de grandes partículas em uma piscina líquida com pequenas partículas). 
CASTRO, W.J.R. et al. Exigências de compostos fibrosos para bovinos em confinamento. PUBVET, Londrina, V. 8, N. 3, Ed. 252, Art. 1667, Fevereiro, 2014.

A FDN fisicamente efetiva vai sempre ser menor que a FDN, no entanto a FDN efetiva pode ser menor ou maior que a concentração de FDN em um alimento. A capacidade da fibra em manter a saúde do animal e a produção de gordura do leite (efetivamente) é denominada de fibra efetiva (FDNe). Para cada unidade de FDN adicionado de uma fonte de fibra não forragem (baixa efetividade), ocorre redução de 0,025\% do teor de gordura no leite Pereira et al. (1999).

O tamanho da partícula da forragem se torna importante, especialmente para manutenção do ambiente ruminal, essencial para assegurar o crescimento adequado dos microrganismos ruminais, o que resulta em um aumento dos AGVs, especialmente o acetato, e a produção de proteína microbiana.

\section{Importância dos compostos fibrosos no confinamento}

A fibra é um componente essencial da dieta dos ruminantes, sendo necessária para obtenção de consumo máximo de MS e energia para estimular a atividade de mastigação e secreção de saliva e manter a porcentagem de gordura no leite, assim como manter o rúmem em condições favoráveis de funcionamento.

Embora o papel da fibra na disponibilidade de energia e fermentação ruminal seja frequentemente reconhecido, o seu papel na regulação do consumo não tem sido muito bem aceito. Muito da controvérsia é devido à falta de reconhecimento da complexidade e interações de compensações que ocorrem ao se determinar o consumo de um determinado grupo de animais alimentados com uma dieta específica Zanine e Macedo (2002).

A fibra insolúvel em detergente neutro (FDN) representa a fração de carboidratos estruturais dos alimentos (parede celular) e tem sido relacionada à regulação da ingestão de alimentos, digestibilidade, taxa de passagem e atividade mastigatória dos ruminantes, dietas com elevada concentração de 
CASTRO, W.J.R. et al. Exigências de compostos fibrosos para bovinos em confinamento. PUBVET, Londrina, V. 8, N. 3, Ed. 252, Art. 1667, Fevereiro, 2014.

fibra, necessariamente, possuem baixa densidade energética e a repleção ruminal limita a ingestão, reduzindo a performance animal Cardoso (2005). Os ruminantes requerem um mínimo de fibra efetiva na dieta para manter uma função normal do rúmen e evitar a ocorrência de distúrbios metabólicos como acidose, que podem comprometer sua performance.

Palucci (2008) afirma que a fibra também estimula a motilidade, que é importante por aumentar o contato do substrato com as enzimas extracelulares dos microrganismos do rúmen, auxiliando na ruminação e na renovação de conteúdo ruminal, ajudando a aumentar a taxa de passagem. A taxa de passagem tem importantes consequências. Ela altera a eficiência da produção microbiana $e$, taxas de passagem mais rápidas favorecem 0 crescimento microbiano. Outro efeito da taxa de passagem, igualmente importante, e que pode ter grande impacto na utilização dos alimentos, é que ela pode alterar a degradação efetiva do alimento. Assim, um alimento que tenha $70 \%$ de digestibilidade com incubação por $24 \mathrm{~h}$, pode ter sua digestibilidade reduzida, caso ele permaneça menos que $24 \mathrm{~h}$ no rúmen.

Mertens (1997), cita que o ajuste da fibra na composição da ração para bovinos é de fundamental importância pela sua efetividade na manutenção da atividade da mastigação e do pH ruminal. Para manter um pH peculiar de 6,2 é necessário que o animal consuma $6,32 \mathrm{~kg}$ de fibra detergente neutro fisicamente efetiva (FDNfe)/dia. Da mesma forma, para manter um $\mathrm{pH}$ típico de 5,9 é necessário o consumo de 3,66 kg de FDNfe/dia. Assim, menos pronunciada, mas talvez cumulativamente mais importante é a acidose ruminal subclínica que ocorre de 1 a 3 horas após uma refeição de concentrados. Isto se deve em parte, à redução do $\mathrm{pH}$ intra-ruminal até valores abaixo do limite para a celulólise e de uma certa forma à aquisição preferencial de substratos metabólicos pelos microorganismos amilolíticos mais competitivos Leek (1993).

De acordo com Turino, (2003) dietas com maiores níveis de FDN e de fibra fisicamente efetiva promovem um aumento da atividade mastigatória em 
CASTRO, W.J.R. et al. Exigências de compostos fibrosos para bovinos em confinamento. PUBVET, Londrina, V. 8, N. 3, Ed. 252, Art. 1667, Fevereiro, 2014.

ovinos confinados. O autor verificou que animais que foram alimentados exclusivamente com ingredientes concentrados, apresentaram tempo médio de ingestão, ruminação e mastigação de 122, 117 e 239 min/dia, respectivamente, enquanto que aqueles que recebiam dietas com $18 \%$ de FDN, tendo como fonte bagaço de cana apresentaram médias de 215, 289 e $503 \mathrm{~min} /$ dia para ingestão, ruminação e mastigação, respectivamente, isso mostra a importância da fibra para animais em confinamento para manter a saúde do rúmem.

Ainda na mesma linha de pesquisa Albright (1993), em experimento com vacas, relatou para três níveis de FDN na dieta (26, 30 e 34\%), valores para os tempos despendidos em ruminação e total de mastigação de 344 e 558; $403 \mathrm{mim} /$ dia, respectivamente. Segundo Van Soest (1994), o tempo gasto em ruminação é proporcional ao teor de parede celular dos alimentos, assim, ao elevar-se o nível de FDN das dietas haverá um aumento no tempo despendido com ruminação.

A trituração da fibra tem dois efeitos; primeiramente ela decresce a atividade de mastigação, normalmente associada a alimentos com elevado teor de fibra, então, esses alimentos não serão tão efetivos na manutenção do pH ruminal quanto forragem longa; em segundo lugar, a trituração eleva o potencial de consumo destes alimentos, porque o volume ocupado pelo alimento moído será menor que aquele do alimento não processado Van Soest (1982). O pH baixo está diretamente relacionado com efeitos negativos na ingestão de energia e absorção de proteína, o qual são os primeiros fatores limitantes na produção Allen (1997). Ainda o mesmo autor coloca que o pH ruminal varia com a refeição e o comportamento de mastigação; o pH decresce no momento da alimentação e aumenta durante a ruminação.

A concentração da FDN dietética não está relacionada diretamente com ० pH ruminal. Entretanto, o FDN dietético está relacionado com o tempo total de mastigação, que por sua vez está diretamente relacionado com o fluxo de 
CASTRO, W.J.R. et al. Exigências de compostos fibrosos para bovinos em confinamento. PUBVET, Londrina, V. 8, N. 3, Ed. 252, Art. 1667, Fevereiro, 2014.

saliva para dentro do rúmen. Matos (1997) relatou que a fibra dietética é importante e necessária para manter o balanço adequado da fermentação no rúmen, prevenindo quedas no seu pH e depressão no teor de gordura do leite. Segundo este autor, a fibra na forma longa estimula o fluxo de saliva, a mistura da digesta no rúmen e a capacidade tamponante do conteúdo ruminal, sendo a FDN, por suas características intrínsecas, responsável direta por porção significativa deste tamponamento. De acordo com Fimbres et al. (2001) ovinos alimentados com altos níveis de concentrado na ração (80-95\% de concentrado) têm redução do $\mathrm{pH}$ ruminal e, desta forma, o aumento da incidência de acidose ruminal.

Segundo Mertens (1987), o consumo de matéria seca é a variável mais importante que influencia a performance animal, sendo inversamente relacionada ao conteúdo de fibra da dieta. Dietas com elevada concentração de fibra limitam a capacidade ingestiva do animal, por outro lado, dietas com teores reduzidos de fibra também resultam em menor ingestão total de MS, uma vez que as exigências energéticas do animal podem ser atingidas em níveis mais baixos de ingestão. De acordo com Pires et al (2000), o consumo de alimento possui grande importância dentro de sistemas de produção de carne, visto que será a partir da ingestão de matéria seca que ocorrerá o fornecimento da quantidade de nutrientes necessários para atender os requerimentos de mantença e de produção dos animais

Zanine e Macedo (2002) cita que os pontos críticos param se estimar consumo, são as limitações relativas entre o animal, o alimento e as condições de alimentação. Se a densidade energética da ração é alta (baixa concentração de fibra) em relação às exigências do animal, o consumo será limitado pela demanda energética deste animal e o rúmen não ficará repleto. Entretanto, parece bastante lógico que se a ração foi formulada para uma densidade energética baixa (teor de fibra elevado) relativa aos requerimentos do animal, o consumo será limitado pelo efeito do enchimento do alimento, se a 
CASTRO, W.J.R. et al. Exigências de compostos fibrosos para bovinos em confinamento. PUBVET, Londrina, V. 8, N. 3, Ed. 252, Art. 1667, Fevereiro, 2014.

disponibilidade de alimento é limitada, nem o enchimento nem a demanda de energia seriam importantes para predizer o consumo.

Segundo Mertens (1999) o valor da FDNfe (FDN da forragem) pode variar de 19 a 23\% dependendo de fatores que afetam a atividade de mastigação, produção de ácidos no rúmen, variações na composição e manejo da dieta, capacidade natural de tamponamento do rúmen e suplementação com substâncias tamponante, esses valores estão próximos aos preconizados pelo NRC 1996 para gado de corte onde a porcentagem de fibra na dieta varia de 5 a $20 \%$ dependendo do nível de tecnologia empregado.

Russel et al. (1992) cita que para cada $1 \%$ de decréscimo nesse teor ( $20 \%$ de FDNfe), ocorre redução de $2,5 \%$ na produção de proteína microbiana. Silva (2009) coloca que para manter a digestão da fibra e produção microbiana máxima, um pH ruminal de 6,2 ou acima é necessário, o qual por sua vez requer no mínimo $20 \%$ de FDNe na dieta. Dietas misturadas, o nível mínimo necessário de FDNe é de $20 \%$ da MS da dieta. Dieta de alto concentrado para maximizar a digestão da FDN e ou produção de proteína microbiana, o nível mínimo necessário de FDNe também é de $20 \%$ da MS da dieta. Portanto, tamanho de partícula, densidade e grau de hidratação, são os maiores fatores na determinação da efetividade da FDN em manter o pH acima de um nível acidótico.

Então, cortar, triturar e peletizar forragem reduz a efetividade da FDN. Portanto, grãos processados (quebrado, laminado, triturado e floculado) têm mais baixos FDNe do que grãos secos e inteiros Preston (1998). Outra ferramenta disponível ao produtor em rações com alto teor de concentrado é a utilização de aditivos como tamponantes e ionóforos, com o objetivo de evitar variações no pH ruminal, pois a fermentação de grandes quantidades de carboidrato não fibroso provoca diminuição no pH ruminal. Segundo Santra et al. (2003) dietas com tamponantes ajudam a prevenir a diminuição do pH ruminal, em cordeiros alimentados com rações de alto grão. Alguns 
CASTRO, W.J.R. et al. Exigências de compostos fibrosos para bovinos em confinamento. PUBVET, Londrina, V. 8, N. 3, Ed. 252, Art. 1667, Fevereiro, 2014.

tamponantes comumente utilizados em confinamentos de alto concentrado são calcário calcítico e bicarbonato de sódio ( $\mathrm{NaHCO} 3$ ).

O bagaço de cana-de-açúcar in natura (BIN), subproduto resultante da moagem de cana-de-açúcar, encontrado com facilidade nas usinas, tem sido utilizado com frequência como fonte de fibra na alimentação de ruminantes de grande porte. Segundo Henrique et al. (2007), esse subproduto é um alimento rico em constituintes da parede celular, contém baixo conteúdo celular e possui baixa digestibilidade e baixa densidade.

O bagaço de cana-de-açúcar tem sido muito utilizado como fonte de volumoso em dietas de alto concentrado. Sua função nesse tipo de dieta é estimular a salivação e ruminação e também formar um "colchão" de fibras no rúmen, aumentando o tempo de permanência do alimento Bulle et al. (2002).

Henrique et al. (1999), estudando o efeito do bagaço in natura e da silagem de milho como fonte de fibra efetiva em dietas de alto concentrado para novilhos em terminação, concluíram que o bagaço pode ser utilizado como fonte exclusiva de volumoso, embora o ganho de peso e eficiência de conversão tenham sido inferiores aos observados com silagem de milho, comparados à mesma proporção de concentrado ( $88 \%$ da matéria seca).

Bulle et al. (2002) testaram três dietas isoproteicas à base de bagaço de cana in natura em tourinhos cruzados e encontraram maior ganho de peso com a utilização de $15 \%$ de bagaço de cana in natura na dieta. Leme et al. (2003) também trabalhando com níveis de inclusão de bagaço de cana in natura com níveis de 15, 21 e $27 \%$ também obteve melhor reposta de ganho de peso no tratamento com $15 \%$ de inclusão do bagaço de cana in natura.

Em dietas com alta proporção de ingredientes concentrados, é mais seguro o uso de um teor mínimo de fibra, capaz de estimular a mastigação e permitir ambiente ruminal adequado para não prejudicar o desempenho animal. Alguns trabalhos indicam que o uso de pequena quantidade de bagaço de cana-de-açúcar in natura como fonte de fibra em dietas para bovinos de 
CASTRO, W.J.R. et al. Exigências de compostos fibrosos para bovinos em confinamento. PUBVET, Londrina, V. 8, N. 3, Ed. 252, Art. 1667, Fevereiro, 2014.

corte pode evitar problemas metabólicos, sem prejudicar o desempenho, quando utilizada alta proporção de concentrado Bulle et al. (2002).

A elevação do nível de concentrado na dieta aumenta linearmente o custo total da mesma, porém, reduz os custos com mão-de-obra, depreciação de equipamentos, custo com volumoso e custo de oportunidade da terra Missio et al., (2009). Ainda o mesmo autor constatou que o aumento da densidade energética nas dietas, por via do aumento de concentrado, diminui a conversão alimentar, pelo fato do aumento das taxas de ganho de peso, porém o aumento do custo da dieta diminuiu a lucratividade.

Missio et al. (2009) chegaram a este resultado provavelmente por aumentar a densidade energética da dieta trabalhando com duas fontes energéticas apenas (milho grão e farelo de trigo), o que pode ter aumentado consideravelmente os custos. Clarindo et al. (2008) avaliaram tourinhos submetidos a dietas contendo $80 \%$ de concentrado e formuladas com milho ou sorgo, obtendo resultados muito próximos em desempenho.

Dietas de alto concentrado utilizam uma fração mínima de fibra, exercendo um efeito mais mecânico do que nutritivo, o que pode causar problemas metabólicos nos animais Katsuki et al. (2009). A elevação do nível de concentrado na dieta aumenta linearmente o custo total da mesma, porém, reduz da mesma forma os custos com mão-de-obra, depreciação de equipamentos, custo com volumoso e custo de oportunidade da terra Bulle et al. (2002).

Sendo assim dietas que contém alta proporção de concentrado além de serem mais caras, podem provocar distúrbios digestivos nos animais, porém cabe aos técnicos fazer um balanço adequado nas dietas que contém alto grão para otimizar os lucros dentro dos confinamentos. 
CASTRO, W.J.R. et al. Exigências de compostos fibrosos para bovinos em confinamento. PUBVET, Londrina, V. 8, N. 3, Ed. 252, Art. 1667, Fevereiro, 2014.

\section{Considerações Finais}

A utilização de um nível adequado de fibra em torno de 15 a $20 \%$ na ração visa obter máxima produção, utilizando-se o máximo de volumoso sem, entretanto, provocar restrição na ingestão alimentar pelo efeito do enchimento do trato gastrintestinal, com consequente comprometimento do desempenho e elevação do tempo necessário para atingir o peso de abate.

\section{Referências}

ALBRIGHT, J.L. Feeding behavior of dairy catlle. Jornal of Dairy Science, v. 76, n.2, p.485$498,1993$.

ALLEN, M. S. Relationship Between Fermentation Acid Production in the Rumen and the Requirement for Physically Effective Fiber. Journal Dairy Science, v. 80, p. 1447-1462, 1997.

BIANCHINI, W.; RODRIGUES, E.; JORGE, A.M.; CANDRIGHETO, C. Importância da fibra na nutrição de bovinos. Revista Electrónica de Veterinaria REDVET, v.7, n.2, 2007.

BUlle, M. L. de M.; Ribeiro, F. G.; LeME, P. R.; TITTO, E. A. L.; LANNA, D. P. D. Desempenho de tourinhos cruzados em dietas de alto teor de concentrado com bagaço de cana-de-açúcar como único volumoso. Revista Brasileira de Zootecnia, v.31, n.1, p.444450, 2002 (suplemento).

CARDOSO, A., R. Níveis de fibra em detergente neutro na dieta de cordeiros confinados na fase de terminação. Santa Maria 2005. (Dissertação Mestrado em Zootecnia) Universidade Federal de Santa Maria (UFSM, RS) 2005.

CARVALHO, S.; KIELING, R. Fibra na alimentação de ruminantes. In: FEIRA DE Iniciação Científica do Centro Universitário Feevale. 2002, Novo Hamburgo. Anais... Novo Hamburgo, 2002. p. 141.

CLARINDO, R. L.; SANTOS, F. A. P.; BITTAR, C. M. M.; IMAIZUMI, H.; LIMA, N. V. dos A.; PEREIRA, E. M. Avaliação de fontes energéticas e protéicas na dieta debovinos confinados em fase de terminação. Ciência Animal Brasileira, Goiás, v. 9, n. 4, p. 902-910, 2008.

FIMBRES, H.; KAWAS, J. R.; HERNÁNDEZ-VIDAL, G.; PICÓN-RUBIO, J. F.; LU, C. D. Nutrient intake, digestibility, mastication and ruminal fermentation of lambs fed finishing ration with various forage levels. Small Ruminant Research, v. 43, p.275-281, 2001.

FREITAS NETO, M.D. Importância da fibra efetiva para bovinos de corte em confinamento. Seminário apresentado a Escola de Veterinária da Universidade Federal de Goiás. Goiânia, 2011. 
HALL, M.B.; Recent adv anced in non- ndf carbohydrates for the nutrition of lactating cows, In: Simpósio internacional em bovinos de leite, 2., 2001, Lavras. Anais... Lavras: UFLAFAEPE, 2001. p.139-148.

MACEDO JÚNIOR, G.L.; ZANINE, A.M.; BORGES, I.; PÉREZ, J.R.O. Qualidade da fibra para a dieta de ruminantes. Ciência Animal, v.17, n.1, p.7-17, 2007.

HENRIQUE, W.; BELTRAME, J.A.; LEME, P.R. et al. Avaliação da silagem de grãos de milho úmido com diferentes volumosos para tourinhos em terminação: Desempenho e características de carcaça. Revista Brasileira de Zootecnia, v.36, n.1, p.183-190, 2007.

HENRIQUE, W. et al. Avaliação do milho úmido com bagaço de cana ou silagem de milho na engorda de bovinos. I. Desempenho animal e características de carcaça. In: REUNIÃO ANUAL DA SOCIEDADE BRASILEIRA DE ZOOTECNIA, 36., 1999, Porto Alegre. Anais... Porto Alegre: Sociedade Brasileira de Zootecnia, 1999. p.307.

KATSUKI, P. A. Avaliação nutricional, desempenho e qualidade da carne de bovinos alimentados com rações sem forragem, com diferentes níveis de substituição do milho inteiro por casca de soja. 2009. 55p. Tese (Doutorado em Ciência Animal) Universidade Estadual de Londrina, Londrina, 2009.

LEEK, B. F. Digestão no estômago de ruminantes. In: Dukes, H. H. Dukes fisiologia dos animais domésticos. 11. ed. Guanabara Koogan:Swenson\&Reece, 1993. cap. 21, p. 353-411.

MATOS, L. L. A importância da fibra para as vacas. In: DIAS, J. C.; COSTA, J. L. (Org.) Forragens para o gado leiteiro. São Paulo: Tortuga; Juiz de Fora: Embrapa - CNPGL, 1997. p. 88-95.

MERTENS, D.R. Creating a system for meeting the fiber requirement of dairy cows. Journal of Dairy Science, v.80, p.1463, 1997.

MERTENS, D.R. Physical effective NDF and its use in formulating dairy rations. In: Simpósio internacional em bovinos de leite, 2., 2001, Lavras. Anais... Lavras: UFLA-FAEPE, 2001. p.2536.

MERTENS, D.R. Predicting intake and digestibility using mathematical models of ruminal function. J. Anim. Sci., 64: 1548, 1987.

MISSIO, R. A. et al. Desempenho e avaliação econômica da terminação de tourinhos em confinamento alimentados com diferentes níveis de concentrado na dieta. Revista Brasileira de Zootecnia, Viçosa, v. 38, n. 7, p. 1309-1316, 2009.

NOGUEIRA, M. P. Importância da gestão de custos: módulo 1. [S.I.]: Agripoint, 2004. pag. 6.

PALUCCI, D.; A importância da fibra efetiva na nutrição de bovinos de corte
confinados. artigo técnico, Publicado em $07 / 11 / 2008$, acessado em: siterehagro/publicacao. do?cdnoticia $=1794$.

PEREIRA, M. N.; GARRETT, E. F.; OETZEL, G. R.; ARMENTANTO, L. E. Partial replacement of forage with nonforage fiber sources in lactating cow diets. I Performance and health. Journal Dairy Science, v. 82, p. 2716-2730. 1999. 
PIRES, C.C., SILVA, L.F., SCHLICK, F.E. et al. Cria e terminação de cordeiros confinados. Ciência Rural, v 30. n.5, p.875-880, 2000.

PRESTON, R. L. Management of high concentrate diets in the feedlot. Simpósio sobre produção intensiva de gado de corte, 82., 1998, Campinas. Anais... São Paulo: CBNA, 1998. 232 P.

RODRIGUES, M.T. Uso de fibras em rações de ruminantes. In: Congresso nacional dos estudantes de zootecnia, 1998, Viçosa, MG. Anais... Viçosa, MG: Universidade Federal de Viçosa, p.139-171, 1998.

RUSSELL, J. B.; O'CONNOR, J. D.; FOX, D. G.; VAN SOEST, P. J.; SNIFFEN, C. J. A net carbohydrate and protein system for evaluating cattle diests. I. Ruminal fermentation. Journal Animal Science, v. 70, p. 3551-3561, 1992.

SANTRA, A. CHATURVEDI, O. H., TRIPATHI, R., KARIM, S. A. Effect of dietary sodium bicarbonate supplementation on fermentation characteristics and ciliate protozoal population in rumen of lambs. Small Ruminant Research, v.47, p.203-212, 2003.

SILVA, H., L.; Dietas De Alta Proporção De Concentrado Para Bovinos De Corte Confinados; Goiânia 2009, Tese (doutorado), Escola de Veterinária da Universidade Federal de Goiás 2009.

TURINO, V.F. Substituição da fibra em detergente neutro (FDN) do bagaço da cana de açúcar in natura pela FDN da casca da soja, em dietas contendo alta proporção de concentrado para cordeiros confinados. Piracicaba, 2003. 60p. Dissertação (Mestrado em Agronomia) - Curso de Graduação Universidade de São Paulo, 2003.

VAN SOEST, P. J. Nutritional ecology of the ruminents. Corvallis, Oregon: O \&Books, 1982. $373 p$.

VAN SOEST, P.J. Nutritional ecology of the ruminant. 2. ed., London, Constock Publishing Associates, USA, 1994. 476p.

VELLOSO, L. Terminação de bovinos em confinamento. s.l.p., s.ed., 1984. mimeo.

WEDEKIN, V. S. P.; AMARAL, A. M. P. Confinamento de bovinos em 1991. Informações Econômicas, SP, v.21, n.9, p.9-18, 1991.

WEDEKIN, V.S.P.; BUENO, C.R.F.; AMARAL, A.M.P. Análise Econômica do confinamento de bovinos. Informações Econômicas, SP, v.24, n.9, 1994.

WEISS, W. P. Dietary fiber requirements of dairy cattle explored. Feedstuffs, v. 65, n. 46, p. 14-17, 1993.

ZANINE, A.M.; MACEDO JUNIOR, G.L. Importancia do consumo da fibra para nutricao de ruminantes. Revista Electrónica de Veterinaria REDVET, v.7, n.2, 2006. 